\title{
A perennial problem in gendered participation in music: what's happening to the boys?
}

\author{
Scott D. Harrison \\ Griffith University, P0 Box 3428, South Brisbane 4101, Australia \\ scott.harrison@griffith.edu.au
}

Despite three decades of research, gendered participation in music continues to be problematic. While many aspects of Western society maintain a patriarchal stance in the workplace, it is apparent that girls have made some significant changes in their musical choices. Males, it seems, are maintaining the same preferences for instruments as they did 100 years ago, avoiding 'gentler pursuits' like singing and playing the flute. This paper seeks to investigate the continued existence of stereotyping of musical participation and to discover some of the underlying reasons for this in the musical choices for boys through the literature. Furthermore, themes arising from existing research are investigated through fieldwork recently conducted in Australia.

\section{Preamble}

Despite significant research into the field of sex stereotyping of musical instruments, familiar trends recur in the music classroom: almost no boys singing in a co-educational environment; small numbers of boys playing flute and other so-called 'feminine' instruments. Similarly, girls' lack of participation in lower brass and percussion and in popular music is evident in schools and professional environments. These issues confront practising educators every day. This research therefore reviews recent literature in the field in an attempt to establish the continued existence of stereotypes and, through more recent fieldwork, offers a fresh perspective on what the causal factors might be.

Underpinning the study is an acknowledgement that gender is a fluid entity with situational, definitional and cultural factors. As a result of these interweaving elements, the study of gender is a complex combination of separate, but interconnected issues. Recent investigations in this field have created the distinct categories of sex (as a biologically determined entity), sex roles (the performance of roles typically associated with biological sex), sexuality (the preference for male and/or female partners and the performance of the acts associated with those preferences) and gender (the societal expectations associated with a biologically determined entity). Gender fluidity acknowledges that there is little foundation in the erroneous association of biological sex with the societal functions one performs. Yet, as Taylor (2007) notes succinctly:

... sex is understood as a binary biological given and gender is culturally inscribed on the basis of sex. Sexed bodies are hierarchically arranged on the basis of gender 
(female subordinates male) and are prescribed a culturally appropriate sexual role, which is the compulsory assertion of heterosexuality (Taylor, 2007: 7).

A post-feminist view (as espoused by Benjamin, 1995; Horrocks, 1995; Kipnis, 1995) has provided the motivation for this study. Post-feminists support the claims of women for social, political and economic equity, simultaneously expressing similar concerns for men and boys. There is a danger that male affirming voices taking a post-feminist stance can be seen as misogynist because they challenge feminist doctrines. This is unfortunate because, as Kipnis (1995: 283) claims, critiques of and challenges to feminism need to be viewed as 'more than chauvinism, backlash or counter-social revolution and where proactive male perspectives are not dismissed as implicitly anti-feminist'. The view of some feminists that men have all the power does not accurately reflect the oppression that a number of men experience in race, class and sexual orientation. A post-feminist view is therefore seen as one approach to the study of males' involvement in music, while accepting that other viewpoints contribute to the field of study.

\section{An age-old problem: a selected chronological review of literature}

In A Choir Problem for Today, Grace (1916: 368) commented on 'a shortage of men, boys and money in choirs'. Twenty years later, Damon (1936: 41) described a class of eighth grade boys who 'never sing'. Five years later, Viggiano (1941) attempted to find ways of 'reaching the adolescent who thinks it's sissy to sing'. Another five years later, Winslow (1946: 58) explained that 'probably nothing perplexes the secondary school teacher more than the vocal education of boys... most boys enter high school with negative attitudes towards vocal music and music education in general'. One of the reasons for this, Winslow noted, is that 'vocal music suggests femininity'. By 1957 Forcucci (p. 93) bemoaned the 'noticeable lack of male participants' in music. In her survey of Sexism in Music Education 1972-1982, Pucciani (1983) noted that sex-stereotyping is two-dimensional and discriminates against boys and girls: boys are discouraged from playing the violin; girls are discouraged from playing the trombone.

Abeles and Porter (1978) established a masculine-feminine continuum in which boys' choices were consistently stable at the 'masculine' end of the spectrum (drums, trombone and trumpet) while girls' choices gradually moved towards the 'feminine' instruments (flute and violin). Girls chose a wider variety of instruments, while boys chose almost exclusively from the 'masculine' end of the scale. Abeles and Porter also noted that the association of gender with an instrument often took place prior to instrument selection (between the ages of 8 and 12) and seemed to be a critical factor in that choice.

Griswold and Chroback (1981) surveyed 89 American college students, asking them to rate instruments as masculine or feminine, using a 10-point Likert scale. They found that the most feminine instrument was harp, followed by flute, piccolo and glockenspiel. The role of choral conductor was also considered feminine. The most masculine instrument was found to be tuba, followed by string bass, trumpet, bass drum and saxophone. The instrumental conductor was deemed to be masculine. Fortney et al. (1993: 38) found that 'females tend to play and indicate a preference for flute and clarinet, while males tend to play and indicate a preference for trumpet, percussion and low brass instruments'. 
In 1996, O'Neill and Boulton conducted a study to ascertain whether the divide in terms of girls' and boys' preferences for particular instruments remained as strong as in previous studies. Their main focus was girls' preferences, and they sought to determine whether the rise of feminism and affirmative action had produced any effect. In their results, girls showed a strong preference for flute, piano and violin, while boys preferred drums, guitar and trumpet. The findings also suggested that little had changed with regard to sex-stereotyping of instruments since the early studies of Abeles and Porter (1978).

A shift in approach to gender-related investigations became evident in the 1990s. Focusing less on stereotyping and more on sociological related reasons for instrument choice, Green $(1993,1996,1997)$ concluded that 'both boys and girls tended to restrict themselves or find themselves restricted to certain musical activities for fear of intruding into the other sex's territory, where they may have been accused of some sort of musical transvestism'. Conway's (2000: 8-9) approach also alludes to masculine and feminine associations with instruments: 'I just can't see a guy picking up the flute; it's like such a feminine instrument. It sounds feminine, too' and 'low brass is sort of masculine, but it's not really true at our school, we do have some girls'. Conway (2000) concurs with Green (1997): the barriers for boys are more significant than those for girls, and vocal music is likely to be more of a problem than instrumental music.

Specifically with regard to vocal music, Adler (2001) found that as singing does not construct or defend masculinity, it carries with it gender incongruent and therefore homophobic labels. Adler (2001) and Harrison (2003, 2004) take up the notion of homophobia extensively, with their participants commenting on name-calling using terms such as 'sissy, faggot and poofter' being applied to male singers.

Children as young as five have been shown to display gender-typed preferences (Pickering \& Repacholi, 2001). The most popular choice among boys at this age was the drum. For girls it was the violin. Influences in relation to instrument choice were found to include parental pressure, music teacher's advice, or availability of instruments in the home/school. In a study into early childhood in Australia, Hall (2005: 17) found that 'gender can play a role in boys' construction of musical identities at a young age.' Hall emphasised the need for boys to find multiple ways of expressing masculinity prior to adolescence and encouraged researchers to investigate the phenomenon further to improve boys' engagement in music.

The studies above fall into two categories: research that seeks to prove the existence of stereotyped musical choices, and gender-related studies that examine the association of masculinity and femininity with particular instruments. Early studies noted the concept of 'missing males' as a prevalent phenomenon in music-making, with Winslow referring to feminine associations with singing as early as 1946. The existing research also noted that girls tend to choose a wider range of instruments, perhaps as a result of significant societal change brought about through the rise of feminism. While the literature confirms gender-related reasons for musical choices, there is a dearth of research examining the effects of this in the lives of men. There is also a significant lack of study into singing as an 'instrument'.

The current study follows up some of the themes arising from the literature. The first phase of research recently conducted in Australia seeks to ascertain the extent to which stereotyping continues to exist in music education and includes singing, an omission from 
many of the previous studies. The second phase of the study aims to examine the reasons for the choice of instruments and the effects of musical participation choices in the lives of 21 st century males.

\section{Method}

This project employed a mixed method design. While mixed methods can take a number of forms, this research is based on Patton's (2002) advocacy of combining aspects of qualitative and quantitative data:

Because qualitative and quantitative methods involve differing strengths and weaknesses, they constitute alternative, but not mutually exclusive, strategies for research. Both qualitative and quantitative data can be collected in the same study (Patton, 2002: 14).

Furthermore, the study employs explanatory design (Creswell, 2005), which incorporates the collection and analysis of quantitative data, followed by the collection and analysis of qualitative data. The different methods used ensure that depth and breadth are possible, with each method providing unique and rich data. The survey provided a broad picture of tertiary students' perceptions of the gendering of musical instruments, and interviews were used to investigate males' perceptions in a qualitative way.

Two types of sampling were employed. For the first part of the study, convenience sampling, where participants were selected on the basis of ease of contact, was used. Maximum variation sampling was used to select the participants for the interviews as it enabled the identification of 'common patterns across great variation' (Glesne, 1999: 29). Participants were selected to represent varied experiences of music at school.

The study took place in two phases:

1. Tertiary students were surveyed to ascertain the extent to which the perception of stereotyping of instrument choice was apparent.

2. Adult males were chosen as case studies and interviewed to reflect on their experiences of music at school.

The first phase of the research aimed to examine the nature and extent of stereotyping. As part of a larger study, tertiary students were asked to give an indication of whether certain instruments were perceived as having gender-associated attributes. Students ranged in age from 19 to approximately 50 years of age. Students in music programmes and non-music programmes were surveyed.

These data gathering procedures were chosen because of their foundation in the literature. Phase 1 used tools of Abeles and Porter (1978) and Griswold and Chroback (1981) in an attempt to find correlations with, and variations from their work. Elements of Abeles and Porter (1978: 72) used in this study include the questions:

- Does the association of gender with musical instruments exist in the general population?

- Do musicians and non-musicians have similar gender associations with instruments?

- At what age does sex-stereotyping of instruments begin? 
The use of a masculine feminine continuum developed by Abeles and Porter (1978) proved to be a practical tool, but with a reduced number of instruments and including singing for the first time in a study of this nature. The test instrument was a 10-point Likert-type scale anchored on the words masculine and feminine, similar to that used by Griswold and Chroback (1981).

The second phase involved case studies of 21 men of culturally diverse backgrounds between the ages of 18 and 40 who reflected on their experiences of music at school. The main purpose of this phase was to find out, in the experience of this cohort, some of the causes of gender-based instrument choices evidenced in the perceptions of tertiary students in Phase 1. The focus on adults in this phase of the study was for two reasons: firstly, because of the ethical dilemma of requesting information regarding sex-stereotyping and gender from minors was considered; and secondly, because the reflections of adults brought an objective distance from the events experienced by participants in their school days.

Interviews were used in Phase 2 of the research, defined as 'a purposeful conversation in which one person asks prepared questions (interviewer) and another answers them (respondent)' (Frey \& Mertens-Oshi, 1995: 1). A semi-structured, informal approach was considered appropriate since in 'an informal interview, not structured by a standard list of questions, the interviewer can choose to deal with the topics of interest in any order, and to phrase their questions as they think best' (Nichols, 1991: 131). The semi-structured, informal approach also generated data related, but not central, to the original core purposes of the research. These data, while tangential to the study, provided revealing insights into the gendered musical experiences of males.

On completion of the data-gathering phase, the data were transcribed for 'further comparative examination' (Bartel, 2006: 360), maintaining the integrity of the data and avoiding the tendency to 'dissolve all complexity' (Shenk, 1997: 157). Bartel (2006) describes analysis in music education research as 'a process of simplification, a process of creating order within the represented reality that allows for meaning making'. In analysing the data, the purpose was therefore to find similarities and differences between the two phases and to draw conclusions by triangulating these findings with the literature. The data from both phases of the study were therefore subjected to content analysis (Cavana et al., 2001) to identify themes, concepts and meanings (Burns, 2000).

\section{Results and analysis}

\section{Phase one}

Students $(n=98)$ were surveyed to ascertain the extent to which stereotyping of instrument choice was apparent. Undergraduate music students $(\mathrm{n}=71)$ and non-music students $(n=27)$ from a university in Queensland, Australia participated in the study. Music students were those students enrolled predominantly in music subjects, while the nonmusic students were from disciplines other than music. The gender balance of the music participants was 32 males and 39 females. Non-music participants comprised 9 males and 18 females: total 41 male subjects and 57 female subjects, as seen in Table 1. 
Table 1 Phase 1 participants by type and gender

\begin{tabular}{lccc}
\hline \hline & Music & Non-music & Total \\
\hline Male & 32 & 9 & 41 \\
Female & 39 & 18 & 57 \\
Total participants & & & 98 \\
\hline \hline
\end{tabular}

Table 2 Perceptions of tertiary students in relation to gender attributes of instruments

\begin{tabular}{|c|c|c|c|c|c|c|c|c|c|c|}
\hline \multirow[b]{2}{*}{ Instrument } & \multicolumn{8}{|c|}{ Feminine } & \multicolumn{2}{|c|}{ Masculine } \\
\hline & 1 & 2 & 3 & 4 & 5 & 6 & 7 & 8 & 9 & 10 \\
\hline 'Cello & 10.2 & 2 & 14.3 & 13.3 & 24.5 & 25.5 & 3.0 & 4.1 & 0 & 3.1 \\
\hline Clarinet & 8.2 & 4.1 & 10.2 & 19.4 & 29.6 & 19.4 & 3.1 & 3.1 & 0 & 2.0 \\
\hline Drums & 2.0 & 0 & 0 & 1 & 7.0 & 9.2 & 13.3 & 22.4 & 21.4 & 25.5 \\
\hline Flute & 19.4 & 18.4 & 22.4 & 13.3 & 13.3 & 8.2 & 0 & 1.0 & 2.0 & 2.0 \\
\hline Guitar & 1.0 & 1.0 & 1.0 & 2.0 & 9.2 & 24.5 & 18.4 & 16.3 & 16.3 & 10.2 \\
\hline Sax & 0 & 2.0 & 1.0 & 2.0 & 10.2 & 25.5 & 22.4 & 17.3 & 12.2 & 7.1 \\
\hline Singing & 8.2 & 8.2 & 9.2 & 13.3 & 28.5 & 27.5 & 3.0 & 1.0 & 0 & 1.0 \\
\hline Trumpet & 1.0 & 0 & 1.0 & 7.1 & 8.2 & 10.2 & 21.4 & 17.3 & 19.4 & 13.3 \\
\hline Trombone & 1.0 & 0 & 2.0 & 0 & 5.1 & 12.2 & 17.3 & 28.5 & 18.3 & 17.3 \\
\hline Violin & 9.2 & 8.2 & 10.2 & 10.2 & 29.5 & 27.6 & 3.0 & 2.0 & 0 & 0 \\
\hline
\end{tabular}

The test instrument was a 10-point Likert-type scale anchored on the words masculine and feminine, modelled on Griswold and Chroback (1981). The test listed, in alphabetical order, the names of ten instruments: 'cello, clarinet, drums, flute, guitar, saxophone, singing, trumpet, trombone and violin. Each subject was asked to read the alphabetical list and circle the number (1-10) that applied to their perception of whether the instrument was associated with masculine or feminine attributes, 1 being most feminine. The percentage of respondents who selected each number on the scale for each instrument is presented in Table 2.

It is clear that a number of respondents did not perceive instruments to have gendered qualities: a large proportion of the responses for 'cello, singing and violin were in the centre of the table. This is also true to a lesser extent for clarinet, saxophone and guitar, all of which had some gendered connotations. Flute was clearly considered feminine. Drums and trombone were clearly gendered masculine by a large proportion of subjects. A more detailed analysis of the data indicated that males' perceptions were polarised and females tended to give more conservative responses in the middle of the scale. Music majors tended to have stronger gender associations with instruments than non-music majors. From these data, it was possible to develop a masculine-feminine continuum of instruments (Fig. 1), adapted from previous research by the author in this field (see Harrison, 2001): 


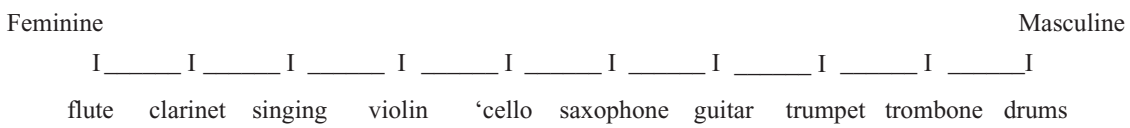

Fig. 1 Masculine-feminine continuum of instrument choice.

The findings from this phase of the study support the research described in the literature, indicating an ongoing association of gender with certain instruments. Phase 2 aimed to explore the reasons for this further.

\section{Phase two}

Males were interviewed in relation to their experiences of music at school. The 21 participants were aged between 18 and 33 years and had attended a variety of state, private, co-educational and single sex schools. Participants were asked to describe their experiences of music at school. Through the use of content analysis (Burns, 2000), the following recurrent themes were identified in the responses:

- Participants' early experience of music

- Situational factors

- Role models

- Music and sport

- The emergence of stereotyping and gender issues in musical activities

In cases where stereotyping and gender-related issues were problematic, harassment of musicians - particularly in relation to homophobic labels noted in Adler (2001) and Harrison (2001, 2003) - was also discussed.

\section{Early experiences}

Many subjects indicated parental influence as a factor in early music making, before contact with teachers through school. For Kevin it was a case of being surrounded by classical music in the preschool years:

Kevin: My first experiences of music were probably as a little boy (3-6 years old) with my parents playing popular Classical Music on the record player. This was the only music that was played.

For Jeffery, the influence of the parent was in an accidental, yet defining moment:

Jeffery: I remember dad getting his hands on this video called The Complete Beatles... There sitting at the back of the band on his little platform, playing away was Ringo. I remember just seeing him and being blown away and thinking, "wow what a great job". You don't have to sing or do anything like that, you just play.

The accidental nature of discovering musical interest was not always in the presence of a parent. Other family members had also played a pivotal role: 
Brian: We went to my grandmother's and a family friend brought his old trumpet around. The first time I picked it up I produced a good solid tone so I found the instrument that was suited. That weekend grandma and grandad bought me my first trumpet and I sat and blew for hours in their music room, excited that I was able to make a noise and therefore able to play in the band.

While it may be difficult to prove the biological precursors of musical ability, the influence of families in providing early musical opportunities was noteworthy. The role of teachers as early influencers of musicians was significant for some participants. Blake supports this view in describing his first teacher:

Blake: My first guitar teacher was a man who really instilled a love of music in me. He encouraged me to write my own songs and gave me many opportunities to perform these.

There were a small number $(n=3)$ of participants for whom warmth and enthusiasm did not feature in their early recollections. Bruce and Benjamin had strong, but unpleasant memories of their private music lessons:

Bruce: In grade three, I began learning piano from a very old and scary private teacher who eventually began to suffer from incontinence making piano lessons a very aromatic experience.

Benjamin: When I started school I took up the piano but this was a very short-lived experience as my piano teacher was a particularly nasty woman. I quickly told my parents that I was no longer interested in playing the piano.

For both subjects, this first experience was 20 years before this investigation took place, yet the memory was quite vivid. Bruce and Benjamin had persevered with music, despite these encounters.

Class music teachers were also scrutinised. In the case of Glen, music in Year 8 was the last general music experience to which students were exposed before proceeding to elective classes. While it is generally agreed that music making is an enlightening, happy enterprise, this was not Glen's experience.

Glen: Music was compulsory in Year 8; it was often the worst subject because the Music Director was the angriest teacher in the school.

As found by Collins (2005), early experiences of music were critical determinants in the level and type of involvement in the music making of these young men. Family, studio music teachers and classroom teachers all contributed to decisions about instrument choice and subsequent participation in music.

\section{Situational factors and role models}

Situational factors were a feature of some participants' $(n=14)$ views of the construction of gender. The role of singing was scrutinised and, as Maurice found, can fluctuate according to the broad culture in which one works: 
Maurice: ... people heard that I sang opera and they immediately assumed that I was gay. Again, this wasn't a problem, but it goes to show how narrow minded our culture is in Australia that we can't accept 'real men' to be artists.

This view concurs with those of Adler (2001) and Harrison (2003, 2004, 2006). Parental influence, as outlined earlier, had a profound effect on some participants' introduction to music. This was not true of all subjects, some of whom found that this support did not continue beyond the early stages into secondary school and beyond:

Bruce: My father has only accepted that music can be more than a hobby in the past few years.

Kevin: When I reached grade 7 for some reason I decided to give it all up and let it all slide, for reasons unknown to me. I stopped practising and stopped lessons ... I wanted a normal and enjoyable childhood. I think this came from the pressures my parents put on me as well as teachers, to succeed and be the best.

Gerard found that his parents were concerned about associations of the arts with homosexuality and therefore discouraged his involvement:

Gerard: I decided to become a Music Theatre performer - to rise above the other [expletive] boys at school. I also secretly loved to dance but my parents didn't encourage it because of its association with homosexuality.

The focus and responsibility of schools was raised by two participants who refer specifically to the place singing held in their school culture:

Richard: It [my school] wasn't really a place for singers because it wasn't considered 'normal' for a young man to sing.

Simon: Kind of being on the outside of things as a rather odd faggoty [sic] person at my school, singing did little to boost my social standing.

Richard and Simon present one viewpoint as to the nature of their school community, but Barry and Blake provided an alternative, more positive stance:

Barry: Music was considered fairly highly in the school community. With many wins in local competitions and the fact that music was such a part of life at school masses, concerts and ceremonies, that music was just another avenue for students to experience.

Blake: I believe that the school structure was conducive to allowing students to be able to pursue their own interests and provided ample opportunities to further learn and grow.

Narrowing the focus in schools further, Shane and Fredrick reflected on the role of staff and other musicians as having a long-term effect:

Shane: The hardest time I received about being a musician was from staff and other musicians. Staff told me I should ignore musical endeavours and concentrate on my academic pursuits. I followed this idea of not doing music straight out of school, which I really shouldn't have. So this staff pressure did influence my music career. 
Fredrick: Thanks mainly to the music teachers at that time, we were given the opportunity to do and see things that your average student would not... it was during this part of my life that I began thinking about continuing music as a full-time career.

Some participants $(n=17)$ noted the importance of having strong relationships with the studio teacher, the class music teacher and/or the music director. Richard notes that competence as well as enthusiasm was relevant.

Richard: I loved my lessons with my singing teacher. The most important thing I got out of all of this was I had found something I was enjoying immensely. There's another teacher I have a lot of respect for: he worked hard at encouraging young men to sing and took every opportunity to have us perform.

The influence of the macro environment (national culture) alongside the microcosms of schools, classrooms and individual mentors clearly affected aspects of participation for these men.

\section{Music and sport}

The distinctive Australian emphasis on sport has been the topic of ongoing investigation by the author (Harrison, 2003, 2005). This study reaffirmed many of the earlier findings, but with a particular emphasis from almost all respondents $(n=19)$ on the relative status of music and sport in the educational setting. In these cases, music came second to sport.

Brian: I just never hung around people that I thought would give me crap - and that was just about everybody. Basically you either did sport (very accepted, supported and praised) or you did music (very uncool and nerdish).

Fredrick: Although music was an important part of the school in terms of the role it played in ceremonies at the school and the promotion of the school through outside performances, it always took second place to sport by a fair distance and was not looked upon favourably whenever it clashed with sport-related events.

There were also two instances of the complementary nature of music and sport. Some of these referred to individual students, others were part of an institutional agenda. For Richard it was a recollection of an individual who crossed the institutional divide, while for Blake it was a school policy that made the difference to his experience:

Richard: There was a senior student who played 3rd clarinet in the concert band. He was selected in the $1 \mathrm{st} X \mathrm{~V}$ rugby team. He brought many of us in the band closer to rugby.

Blake: Even the jocks had to play an instrument, and it usually worked out that the people who were in any leadership position in the school were involved in the musical programme as well as sporting.

Music and sport can have complementary roles (see Harrison, 2005), if the individuals involved can overcome the cultural issues played out through school traditions and media attention. 


\section{Gender and stereotyping}

Phase 1 results indicated a strong perception of femininity with instruments such as flute, clarinet and singing. Males, through their interviews, indicated a range of behaviours that inhibited a complete musical experience, related to the playing of these instruments:

Brian: There must have been some harassment about playing the clarinet because I took up the trombone because I felt it was more manly.

Garry recorded a similar response, claiming the pitch and/or timbre of the instrument was related to whether it was considered 'masculine' or not:

Garry: In high school about Grade 9 I gave the violin away and took up the 'cello, the reason for this was that violin wasn't seen as a very boy [sic] instrument and if I was going to play a stringed instrument it would be the cello as I saw it as more manly, I guess being deeper sounding or something: stupid I know!

Early influences and situational factors (including role model, location and the interaction of music with sport) contributed to views of instruments as having gendered attributes. As a result of gendered instrumentation (i.e. the description of an instrument as masculine or feminine), some participants reflected on the social cost of being involved in certain types of music.

\section{Harassment}

For some interviewees $(n=4)$, there were vivid memories of themselves and others paying a price for the playing of particular instruments. This was accentuated in those instruments found in Phase 1 to have 'feminine' qualities. Singing was one activity singled out by Fredrick and Richard:

Fredrick: I can remember a musician being hassled - it was the Italian singer. When he sang in front of the whole school in Year 8 he was mocked for his high voice and when in later years he moved to Elvis songs, they knocked him now and then ... He copped a lot of flak, mostly about his voice, especially from the older kids whose voices had broken.

Richard: All through most of my High School life I had to persevere with a lot of nasty comments and rumours from most of the mainstream students and for a while I was alienated purely because I enjoyed singing. The really sad stuff happened in my earlier years though, Years $9 \& 10$. I couldn't sit through a lunch-hour or recess without people screaming things at me and throwing pieces of food at me. For a while it was really terrible.

Richard's reference to verbal harassment brought probing as to the content of these taunts. Fredrick and Maurice reflected on the homophobic content of these comments. Associations of specific musical choices with homophobia have been a consistent thread in the work of Adler (2001) and Harrison (2003; 2004; 2005). Like Richard, they found this behaviour occurred in Years 9 and 10. 
Fredrick: The fact that I was an artistic and sensitive person, proved something many boys (particularly in first three years) could not handle. I was teased with many slang homosexual names and questioned with regard to my sexuality. There was nothing to warrant this, I was clearly not homosexual but this was the way they dealt with me and the fact that I was a little different.

Maurice: Then came high school. It was no longer 'cool' to do music. From the moment I started high school to the year I finished, came the taunting. The name-calling started. Poofter, Faggot, Queer. You name it; I copped it. If it weren't for my passion to do music, I would not be where I am today. For 5 years I put up with this, even having to change schools in year 10. Unfortunately, nothing changed and it was then I knew that if I wanted to continue music I would have learnt to deal with the teasing that came along with it.

These comments are most disturbing in the implication that this type of harassment can curtail musical participation and therefore form the basis for ongoing inquiry into this field.

\section{Conclusions}

The research concluded that, while much effort had been put into addressing the differential involvement of each sex over an extended timeframe, the underlying gender-related reasons had not been fully addressed. The first phase of the research determined that masculinefeminine perceptions of musical participation continue to exist in the minds of both musicians and the broader population. The second phase discovered, through in-depth interviews, some of the reasons why these perceptions persist. As the study of boys' participation has often been viewed from a feminist perspective, boys have been less fortunate than girls and remain restricted by the gender order. There are isolated examples of this being overcome, which form the basis for investigating best practice.

Music educators need to be vigilant in addressing this problem. Initially, this can be achieved by challenging popular stereotypes through the interrelated but separate facets of music, sex, sex roles, sexuality and gender. The post-feminist view underpinning this research acknowledges both the separation and inter-connectedness of these issues. A number of strategies for managing gendered views and behaviour in music have been suggested by the literature and through this research. These include:

1. Role models: teacher, community, industry and student

2. Engagement and training of suitable personnel

3. Producing music of a high standard that commands the respect of the community

4. Providing a variety of opportunities for boys and girls to participate in a range of music and non-music activities including the cautious use of sporting analogies for engagement and training of musicians.

The management of gender issues in music education demands the attention of the musical community. Too few students are able to realise their full potential as a result of stereotyping and other gender-related societal forces. As an academic community, there is a responsibility to provide a strong philosophical background and informed leadership 
without restricting practices that may work in specific situations. As practising music educators the challenge is to examine attitudes and beliefs of self, situation and students. Research and practice must interact to resolve these issues for the sake of boys and girls involved (or, more importantly, not involved) in fully experiencing music.

\section{References}

ABELES, H. F. \& PORTER, S. Y. (1978) 'The sex-stereotyping of musical instruments', Journal of Research in Music Education, 26, 65-75.

ADLER, A. (2001) 'Male gender issues in music education: a three dimensional perspective'. Paper presented at Research in Music Education Conference, Exeter University, April.

BARTEL, L. (2006) Trends in data acquisition and knowledge. In R. Colwell (Ed.), MENC Handbook of Research Methodologies (pp. 343-85). Oxford: Oxford University Press.

BENJAMIN, O. (1995) 'Healing, community and justice in the men's movement: toward a socially responsible model of masculinity', in M. Kimmel (Ed.), The Politics of Manhood (pp. 151-75). Philadelphia: Temple University.

BURNS, R. (2000) Introduction to Research Methods (4th edn.). Sydney: Pearson Education Australia.

CAVANA, R. Y., DELAHAYE, B. L. \& SEKARAN, U. (2001) Applied Business Research: Qualitative and Quantitative Methods. Brisbane: John Wiley and Sons.

COLLINS, A. (2005) 'Boys and Music: What encourages boys to remain involved and motivated in music education in their secondary school years?' Unpublished Master of Education Thesis Deakin University.

CONWAY, C. (2000) 'Gender and musical instrument choice: a phenomenological investigation', Bulletin of the Council for Research in Music Education, 146, 1-15.

CRESWELL, J. W. (2005) Educational Research: Planning, Conducting, and Evaluating Quantitative and Qualitative Research (2nd edn.). Upper Saddle River, NJ: Pearson Education.

DAMSON, I. F. (1936) 'The boys who did not sing', Music Educators' Journal, 23, 41-3.

FORUCCI, S. L. (1957) 'The crime against the singer', Music Educators' Journal, 43, 93-4.

FORTNEY, P. J., BOYLE, J. D. \& DE CARBO, N. J. (1993) 'A study of middle school band students instrument choices', Journal of Research in Music Education, 41, 28-39.

FREY, J. H. \& MERTENS-OSHI, S. (1995) 'How to conduct interviews by telephone and in person', The Survey Kit Vol. 4. London: Thousand Oaks.

GLESNE, C. (1999) Becoming Qualitative Researchers: An Introduction. New York: Longman.

GRACE, H. (1916) 'A choir problem of today', The Musical Times, 57, 367-9.

GREEN, L. (1993) 'Music, gender and education: a report on some exploratory research', British Journal of Music Education, 10, 219-53.

GREEN, L. (1996) 'The emergence of gender as an issue in music education', in C. Plummeridge (Ed.), Music Education: Trends and Issues (pp. 41-58). London: University of London Institute of Education.

GREEN, L. (1997) Music Gender and Education. Cambridge: Cambridge University Press.

GRISWOLD, P. A. \& CHROBACK, D. A. (1981) 'Sex-role associations of musical instruments and occupations by gender and major', Journal of Research in Music Education, 26, 57-62.

HALL, C. (2005) 'Gender and boys' singing in early childhood', British Journal of Music Education, 22, $5-20$.

HARRISON, S. D. (2001) 'Real men don't sing', Australian Voice, 11, 31-36.

HARRISON, S. D. (2003) 'Music versus sport: what's the score.' Australian Journal of Music Education, 1, 10-15,

HARRISON, S. D. (2004) 'Engaging boys - overcoming stereotypes', Choral Journal, 45, 25-9. 
HARRISON, S. D. (2005) 'Music and sport: new approaches to scoring', Australian Journal of Music Education, 1, 56-61.

HARRISON, S. D. (2006) 'Engaging boys in a sequential, voice-based program', Bulletin of the Kodály Music Education Institute Australia, 6-13.

HORROCKS, R. (1995) Male Myths and Icons: Masculinity in Popular Culture. New York: St Martins Press.

KIPNIS, A. (1995) 'The postfeminist men's movement', in M. Kimmel (Ed.), The Politics of Manhood (pp. 275-86). Philadelphia: Temple University.

NICHOLS, J. (1991) A Practitioner's Handbook for Institutional Effectiveness and Student Outcomes Assessment Implementation. New York: Agathon Press.

O'NEILL, S. A. \& BOULTON, M. J. (1996) 'Boys' and girls' preferences for musical instruments: A function of gender?', Psychology of Music, 24, 171-83.

PATTON, M. (2002) Qualitative Research and Evaluation Methods. (3rd edn). Thousand Oaks: Sage.

PICKERING, S. \& REPACHOLI, B. (2001) 'Modifying children's gender-typed musical instrument preferences: the effects of gender and age', Sex Roles, 45, 623-42.

PUCCIANI, D. (1983) 'Sexism in music education: survey of literature 1972-1982', Music Educators' Journal, 70, 1.

SHENK, D. (1999) Data fog: Surviving the Information Glut. New York: Harper Edge.

TAYLOR, J. (2007) 'Pink noise: queer identity and musical performance in Brisbane, Queensland', Queensland Review, September, 2007.

VIGGIANO, F. A. (1941) 'Reaching the adolescent who thinks its sissy to sing', Music Educators' Journal, 27, 62-3.

WINSLOW, R. W. (1946) 'Male vocal problems in the secondary school', Music Educators' Journal, 32, 58-61. 